Rodrigo Polanco, Pbro.

Profesor de la Facultad de Teología

Pontificia Universidad Católica de Chile

\title{
La Iglesia como espacio sagrado de encuentro
}

Nos proponemos entregar algunas pistas para comprender mejor la realidad de la Iglesia como "sacramento o signo e instrumento de la unión íntima con Dios y de la unidad de todo el género humano" (LG 1), es decir, como espacio sagrado de encuentro.

En primer lugar aclaremos que cuando hablamos de espacio sagrado aludimos a aquella o aquellas realidades que refieren al fundamento trascendente de toda criatura que es además condición de posibilidad de toda existencia. Espacio sagrado es, en un sentido muy básico, aquel lugar o situación que permite al hombre experimentar su condición de criatura y de esencial dependencia, a partir de la experiencia todavía anterior de Aquello que es "absolutamente inaccesible", pero del cual a la vez dependo radicalmente (1).

Y cuando hablamos de espacio de encuentro no nos referimos a un espacio mensurable y geométrico, sino al espacio originario "de lo que está a la mano" (2), de lo familiar. Es aquella "zona" en donde encuentro las cosas, en donde ellas se acercan y son "útiles" para mí. Y en cuanto sagrada, esa zona se hace teofánica en tanto que signo de la divinidad, remite al fundamento y expresa lo trascendente.

Decimos esto para focalizar el tema de la Iglesia, no principalmente en los aspectos espaciales externos (templo, lugares), sino en su constitución fundamental, como "acontecimiento institucional" de encuentro.

\section{LA IGLESIA COMO ESPACIO SOCIAL DE LA FE}

Si recurrimos a algunos aspectos de la teoría de la acción comunicativa (3) podemos afirmar que la Iglesia es "el espacio social" de la fe. En efecto, toda acción en donde los hombres intentan entenderse entre sí, a pesar de todos sus límites y fallos, supone una estructura comunicativa que permita tal comunicación. Entraña un consenso mínimo que permita esa comunicación: objetivos comunes, expectati-

(1) Cf. R. OtTo, Lo santo. Lo racional y lo irracional en la idea de Dios (Madrid 1980), 14-21.

(2) Cf. M. HeidegGer, Ser y tiempo (Santiago 1997), § 22-24.

(3) Cf. J. Habermas, Teoría de la acción comunicativa, 2 vol. (Madrid ${ }^{2} 1988$ ). Siguiendo en esto a M. KEHL, La Iglesia. Eclesiología católica (Salamanca 1996), 119-144. 
vas compartidas, y el supuesto fundamental de que se desea y se es capaz de comunicarse. En ese sentido todo acto comunicativo supone una comunidad de comunicación "ideal" como condición de posibilidad trascendental para tal comunicación (4). A la luz de eso, en un primer nivel de comprensión, podemos concebir a la Iglesia como ese espacio "ideal" que permite la fe y el encuentro con Dios. Ahora bien, este espacio social mediador supone algo común entre los sujetos comunicantes, un medio de coincidencia que no se identifique sin más con esos mismos sujetos, que a su vez son diversos entre sí. Supone entonces "un 'medio' social diverso de ellos, relativamente autónomo y capaz de conciliarlos entre sî" (5). Sin embargo, este medio social no se da con total independencia de los sujetos, sino que se realiza como su expresión objetivada, mediante el lenguaje. La comunidad es el resultado de la interacción de las personas, pero a la vez, es el espacio posibilitador de esa misma interacción y comunicación. De ahí que se pueda afirmar que la comunidad es algo más que la suma de sus miembros.

Podemos afirmar entonces que la Iglesia como comunidad de fe ha surgido de la acción del Espíritu y de la respuesta de fe de los hombres, pero a la vez, es el supuesto teológico de la fe, y por lo tanto, posee "una prioridad relativa ante los distintos creyentes" (6). En efecto, así como la comunicación interhumana se realiza en referencia a una comunidad de comunicación universal, así también la comunidad de los creyentes se constituye en referencia al reino de Dios presente germinalmente en la Iglesia (cf. LG 5). Ahora bien, este espacio social de la fe es el mismo Pueblo de Dios, todos los bautizados, que realizan de una manera común los diversos modos existenciales de la fe común. Es la forma institucional-sacramental de la Iglesia y las diversas formas sociales de vida que plasman el modo de vida creyente. Todo ello nace como expresión objetivada de la fe individual, pero a la vez es más que ella y es anterior a la fe de cada individuo: le es transmitida a cada generación desde el inicio, salvando con ello la identidad y la integridad de la fe y por lo tanto de la "res" a la que ella apunta: el Dios revelado por Cristo.

Así pues, la Iglesia como espacio social de la fe es mucho más que la simple reunión de los creyentes. Como espacio "vital" de la fe, ella está dada constitutivamente en cada realización personal, en cuanto sacramento de la presencia y acción de Cristo y del Espíritu, y por lo tanto, "como fundamento de posibilidad de la fe personal y comunitaria" (7). La Iglesia transmite a cada creyente la fe común y la articula en cada uno de ellos a modo personal y comunitario, en cuanto espacio de encuentro con el Dios revelado por Jesucristo. Eso significa que la Iglesia es sacramento, es decir, signo e instrumento de comunión con Dios y los hombres. Veamos ahora los fundamentos teológicos de estas afirmaciones.

(4) Cf. M. KeHL, La Iglesia..., $128 \mathrm{s.}$

(5) M. KEHL, La Iglesia..., 131.

(6) M. KeHL, La Iglesia..., 137.

(7) M. KeHL, La Iglesia..., 141. 


\section{LA ENCARNACIÓN Y LA SACRAMENTALIDAD DE LA CREACIÓN}

Con la encarnación del Verbo, Dios ha entrado en la historia espacio-temporal de la humanidad de una manera escatológica, es decir, universal y definitiva. Esa fue la pretensión inaudita de Jesús (cf. Lc 14, 26; 17, 20s; Jn 14, 6) y la convicción de la primitiva comunidad cristiana, desde sus mismos orígenes, al reconocer que "el Señor crucificado y resucitado, es de forma definitiva y absoluta la norma y la medida de la historia" (8). Jesús es entonces -en palabras de Rahner-, el Salvador absoluto. Es decir, es "aquella personalidad histórica que, apareciendo en el espacio y el tiempo, significa el principio de la autocomunicación absoluta de Dios que llega a su fin, aquel principio que señala la autocomunicación para todos como algo que acontece irrevocablemente y como inaugurada de manera victoriosa" (9). Sin embargo, "no puede ser simplemente Dios como el actor mismo que obra en el mundo; debe ser un trozo del cosmos, un momento de su historia y, además, en su punto cumbre" (10). Significa tanto la autocomunicación misma, como su aceptación. Por eso el dogma cristológico afirma que "Jesús es verdaderamente hombre, verdaderamente un trozo de tierra... un momento en la historia natural humana, pues 'nació de una mujer' (Gál 4, 4)" (11). Es el absolutum que ha devenido concretissimum.

Ahora bien, si la Palabra del Padre se ha revelado de manera definitiva y universal cuando ha devenido un concretissimum situado histórica y temporalmente, entonces lo histórico, temporal y concreto -lo finito-, ha llegado a ser lugar y medio de salvación. Esto nos invita a reconocer que la realidad creada, y los hombres en particular, pueden ser, en cuanto signos y también como instrumentos, mediación de Dios, sacramento de su presencia. La humanidad ha quedado "sacralizada" con la encarnación. Dios se compromete verdaderamente con nuestra finitud, la asume como suya, la salva y la hace definitivamente espacio de salvación. Esto se puede ver de modo especial en las palabras de Mt 25, 40: "Cuanto hicisteis a uno de estos hermanos míos más pequeños, a mí me lo hicisteis". Jesús mismo reconoce a cada una de las acciones corpóreas materiales, gracias al amor que ellas reflejan, un peso infinito, ya que el mismo Verbo encarnado se encuentra presente de algún modo en cada ser humano (12). La humanidad entera es sacramento de Dios y "espacio" de encuentro con él ya que ha sido creada y redimida por el Verbo que asumió carne. En efecto, "el Hijo de Dios, con su encarnación, se ha unido, en cierto modo, con todo hombre... y el Espíritu Santo ofrece a todos la posibilidad de que, de un modo conocido solo por Dios, se asocien a este misterio pascual" (GS 22).

Sin embargo, "Dios que cuida paternalmente de todos, ha querido que todos los hombres formen una única familia... haciendo de uno todo el linaje humano" (GS 24). Por eso mismo "quiso santificar y salvar a los hombres no individualmente y

(8) B. FORTE, La Iglesia de la Trinidad. Ensayo sobre el misterio de la Iglesia comunión y misión (Salamanca 1996), 109.

(9) K. RAHNER, Curso fundamental sobre la fe. Introducción al concepto de cristianismo (Barcelona 1989), 233.

(10) K. RAHNER, Curso fundamental..., 235.

(11) K. RAHNER, Curso fundamental..., 235.

(12) Cf. P. HÜnermann, Dimensioni antropologiche della Chiesa, en W. KeRN - H.J. POTTMEYER - M. SECKLER (EDS), Corso di teologia fondamentale, III: Trattato sulla Chiesa (Brescia 1990), 177. 
aislados, sin conexión entre sí, sino hacer de ellos un pueblo" (LG 9). Asimismo la promesa del reino definitivo es participación en el banquete de bodas del Cordero, en donde todos seremos "uno en Cristo" (Gál 3, 28). De modo que no solo cada "individuo", sino la humanidad como tal, es decir, en cuanto familia de Dios y comunión, ha quedado constituida en cierto modo, en sacramento del encuentro y espacio de salvación. Es la "Iglesia universal" a la cual pertenecen "todos los justos, desde Adán, desde el justo Abel hasta el último elegido” (LG 2).

\section{LA IGLESIA EN CUANTO SACRAMENTO DE SALVACIÓN Y CUERPO DE CRISTO}

Ahora bien, este elemento concreto y espacial que es esencial a la revelación cristiana implica de por sí el recurso a la Iglesia, "espacio social" de encuentro con Dios y salvación "a la mano". Efectivamente, la universalidad y definitividad de la salvación traída por la figura histórica y espacialmente delimitada de Jesucristo, encarnado, muerto y resucitado, como mediador visible y sensible entre Dios y los hombres, implica que esa misma salvación y ese mismo mediador deben continuar presentes y actuantes en la historia humana presente y futura, también de un modo visible y sensible -espacial y temporalmente delimitado- hasta el fin de los tiempos. Así pues, a partir de la encarnación del Verbo, la salvación ha quedado marcada por este principio encarnatorio, de tal manera que siempre la salvación de Dios llega a través de mediaciones categoriales que explicitan la entrega trascendental de todo hombre a Dios. La Iglesia está entonces constituida como presencia permanente de Cristo, para mediar en la entrega de todos los hombres a Dios, a través de Cristo. Justamente, "la Iglesia es el acontecimiento de la actualización de Jesucristo y de su salvación definitiva para los hombres" (13). Esto "significa que la salvación ofrecida por Dios en Jesucristo y en el Espíritu Santo se nos da como tal en el signo finito y pecador de la Iglesia" (14). Todo lo que Dios realizó en Jesucristo para nosotros, se hace presente y actual hoy por la fuerza del Espíritu Santo en los actos centrales de la vida de la Iglesia. Cristo no se ha retirado del mundo después de su ascensión a los cielos, sino que sigue presente, a través de su Espíritu, en la Iglesia. Es en la misma creación en donde nos encontramos con el único Absoluto. Y todo esto a pesar de que los actos centrales de la vida de la Iglesia que hacen presente a Cristo están también siempre marcados -en un sentido ahora negativo- por la finitud humana, de modo que la salvación no se identifica sin más con esos actos. Pero ellos son ciertamente aptos para actualizar la plenitud del amor salvador de Dios en Jesucristo, aunque de modo imperfecto, por su figura finita, humana y pecadora. La Iglesia hace presente la salvación de Jesucristo totum, sed non totaliter. Y en ese sentido, la Iglesia es también revelación de Dios en su trascendencia: La Iglesia es Iglesia y no Dios, es medio y no fin.

Todo esto es lo que el Concilio Vaticano II ha querido afirmar cuando ha declarado que Cristo constituyó a su Iglesia como sacramento universal de salva-

(13) M. KeHL, La Iglesia..., 73.

(14) M. KeHL, La Iglesia..., 74. 
ción (cf. LG 1; 48; 59). En efecto, en el núcleo de la relación del hombre con Dios está el elemento histórico y social, de modo que esa relación tiene un elemento perceptible, histórico y concreto -espacial- en el cual y a través del cual se realiza la definitiva autocomunicación de Dios al hombre en Cristo, y la respuesta del hombre a Dios. Por lo tanto, hay que decir que la Iglesia pertenece a la historia de la salvación, no solo como una organización religiosa útil cualquiera, "sino como la concreción y mediación categoriales de la salvación gratuita" (15) realizada definitivamente en Cristo y el Espíritu Santo. Y eso es lo que entendemos por Iglesia en el sentido más profundo: la comunidad que "parte de Cristo y llega a mí con la exigencia y pretensión de ser la representación de Cristo en la historia perdurante de la salvación, que está acuñada por Cristo" (16).

De modo que hay que afirmar que Jesús propiamente no acabó con los "espacios sagrados", llámense estos templo, lugares de culto, ritos, formas sociales, modos de vida, etc. Jesús solo los transformó y les dio renovada consistencia al dotarlos de una realidad ontológica nueva a partir de su propia corporalidad. Su encarnación constituye el núcleo de todo espacio sagrado, y todo espacio es sagrado en cuanto participa de la encarnación de Cristo. Esto ya lo vislumbró San Pablo al comprender la Iglesia como Cuerpo de Cristo y dotar así a la comunidad creyente de un concepto de esencial importancia para la auténtica comprensión de la realidad de la Iglesia.

El concepto de Cuerpo de Cristo (17) se puede considerar uno de los más maduros resultados de la reflexión neotestamentaria acerca de la Iglesia (18). Es el concepto paulino equivalente al de la vid y los sarmientos de Juan (Jn 15, 1-8); al edificio espiritual que se construye sobre la piedra angular que es Cristo y donde el sacerdocio santo ofrece su sacrificio a través del único sacrificio de Cristo (1 Pe 2, 4s; Heb 13, 15); a la esposa del Cordero (Ap 12, 2.9; 22, 17). Esta noción representa, en el Nuevo Testamento, el elemento unificante del Pueblo con Dios. La Iglesia es el Pueblo de Dios pero reconstruido ahora en Cristo y mantenido siempre en su relación a Cristo: "Todos somos uno en Cristo" (Gál 3, 28). La Iglesia puede ser llamada aquí una personalidad corporativa a la cual cada bautizado pertenece, pero que como totalidad es más que la suma de sus miembros: es realmente el Cuerpo de Cristo. Cada bautizado es incorporado en el único Cuerpo de Cristo por el único Espíritu cuya misión es “cristificar" (1 Cor 12, 12-27; 1 Cor 6, 15-17). A la luz de 1 Cor 10, 16-17 y 1 Cor 11, 27-29 en donde Pablo vincula la Iglesia, como Cuerpo de Cristo, a la eucaristía, cuerpo de Cristo, se puede afirmar que la Iglesia dice relación primeramente a Cristo, y no es simplemente consecuencia de nuestra inserción a él, sino que ella es anterior a nuestra entrada en Cristo. La Iglesia, como Cuerpo de Cristo, nace de la entrega de Cristo por nosotros que ha quedado plasmada en su banquete eucarístico, al cual nosotros nos asociamos. Lo que ocurrió a través del bautismo se acrecienta con una

(15) K. RAHNER, Curso fundamental..., 398

(16) K. RAHnER, Curso fundamental..., 404.

(17) El concepto de cuerpo, en San Pablo y en general en el mundo semita, tiene que ser entendido en el sentido que en un hombre el cuerpo no es una determinada parte de él, sino que es el hombre en un determinado aspecto que es el de la relación con los otros. El cuerpo es lo que permite al hombre el relacionarse con su prójimo y con Dios. El hombre se relaciona en su cuerpo.

(18) R. Schnackenburg, La Iglesia en el Nuevo Testamento (Madrid 1965), 197-210. 
nueva fuerza a través de la eucaristía: insertarse en y ser Cuerpo de Cristo. En síntesis, aquí se presenta la relación entre la Iglesia y Cristo como una profunda unión a través del Espíritu, a la cual se entra por el bautismo y se acrecienta con la eucaristía, que da a los miembros una igualmente profunda unión entre sí y que los obliga a hacer esa unión visible al mundo. La Iglesia es entonces acontecimiento salvífico permanente, es decir, espacio de salvación.

La reflexión posterior de Col-Ef, suponiendo lo anterior, mostró una nueva faceta de este Cuerpo de Cristo. Toma ahora a la Iglesia-Cuerpo como un todo, frente al cual está su cabeza que es Cristo (Col 1, 18; Ef 1, 22-23; 4, 15). Cuerpo, entendido como la propia persona, pero en su capacidad de relación con los otros, muestra a la Iglesia-Cuerpo de Cristo como la presencia de ese mismo Cristo en su relación con nosotros. El cuerpo es lo que le permite al hombre relacionarse con su prójimo y con Dios. Así en la Iglesia, Cuerpo de Cristo, el propio Cristo está presente "para" nosotros. La Iglesia es Cristo en medio nuestro y por lo tanto ella es lugar de salvación, medio de encuentro con Dios, espacio sagrado que liga con el fundamento. Y Cristo, como cabeza, conduce y da vida a su propio cuerpo para que sea lo que debe ser. Cristo es su fundamento imperecedero, su "principio" (Col 1, 18). Cabeza representa para la Iglesia a Cristo en cuanto regala sus dones y llena a la Iglesia de su plenitud (Ef 1,23) y así todos sus miembros, a través de Cristo y en Cristo, son llenados con toda bendición y gracia. Pero además que la cabeza gobierne al cuerpo significa en realidad un servicio y una perenne preocupación de Cristo por su Iglesia como por su esposa (Ef 5, 22-23). La Iglesia como Esposa pasa a través del bautismo y deviene pura y radiante por el poder de la muerte de Cristo. Esto implica también un aspecto de reciprocidad y de estar frente a..., de parte de la Iglesia. Además, el cuerpo puede alcanzar el cielo por su cabeza y así todos sus miembros son hechos hombres perfectos. En Cristo el cuerpo alcanza el cielo (Ef 1, 20-22). De modo que la Iglesia es espacio de salvación en cuanto es acontecimiento de salvación y realización del encuentro con lo sagrado.

\section{LA IGLESIA COMO TEMPLO DEL ESPÍRITU (19)}

Hemos afirmado que la Iglesia llega a ser Cuerpo de Cristo por obra del Espíritu Santo (1 Cor 12, 13). Y de hecho, la comunidad primitiva, desde el inicio, tuvo una muy clara conciencia de haber recibido ese "poder de lo alto" (Lc 24, 49; Hech 1,8$)$ como primer fruto y prenda de la salvación, que la establecía como una realidad sobrenatural ( $\operatorname{Rom} 8,23 ; 2$ Cor 1, 22; Ef 1, 13s). Para la Iglesia apostólica la presencia del Espíritu Santo era una realidad de hecho y que constituía un dato de la máxima importancia, expresado en la gran cantidad de carismas existentes (1 Cor 12-14; 1 Cor 1, 7; Gal 3, 2-5; Rom 12, 6-8). En ese mismo sentido se entiende también la "preocupación" del Espíritu por la suerte de las iglesias en el relato de los Hechos: el Espíritu es el que llama, conduce, ordena y mantiene la acción de la Iglesia: Hech 5, 3.9; 9, 31; 15, 28; 20, 28. La realidad de la Iglesia no puede ser

(19) R. Schnackenburg, La Iglesia en el Nuevo Testamento..., 189-196; cf. A. Antón, La Iglesia de Cristo. El Israel de la Vieja y de la Nueva Alianza (Madrid 1977), 435-437. 
entendida sin ese fundamento y donación desde lo alto por la acción escatológica de Dios (cf. Ez 36, 27; 1 Cor 3, 16s).

Sin embargo, es Jesús el que "exaltado por la diestra de Dios, ha recibido del Padre el Espíritu Santo prometido y lo ha derramado" a nosotros. Pentecostés es entonces la prueba de la llegada de los tiempos escatológicos (Hech 2; Jl 3, 1-5) y de la nueva alianza (2 Cor 3, 6-18). Es decir, solo es posible hablar del pueblo escatológico de Dios si y cuando el Espíritu de Dios ha sido derramado libremente como poder de nueva vida. Por eso el bautismo conferido después de Pentecostés fue entendido siempre como la donación del Espíritu y sus dones escatológicos como frutos de la redención de Cristo. Pero lo importante para nosotros es que el Resucitado envió su Espíritu para construir con él su Iglesia. Ef 2, 20ss muestra con fuerza que "ser morada de Dios en el Espíritu" no significa simplemente que el Espíritu viene solo como complemento posterior después de la fundación de la Iglesia por Jesús. Es mucho más profundo: la comunidad de los discípulos de Jesús solo llega a ser Iglesia a través del Espíritu. De allí el paralelo entre "en el Señor” y "en el Espíritu” del texto de Ef 2, 21-22. La redención de Cristo solo llega a ser efectiva y fructífera a través del Espíritu. El Espíritu Santo hace la Iglesia, es la base fundamental de la auténtica vida de la Iglesia y le da a ella su auténtica naturaleza espiritual.

Esto porque solo se puede reconocer a Jesús como "el Señor", si se es movido por el Espíritu Santo (1 Cor 12, 3). Todo acto de fe se realiza "en” el Espíritu Santo. La Iglesia surge cuando el Espíritu posibilita la fe tanto personal como comunitaria. Esto quiere decir entonces que "la Iglesia constituye siempre el espacio vital que posibilita concretamente esa fe, el espacio donde los individuos recibieron la fe -mediante el anuncio y el bautismo- y la desarrollan -mediante la participación en todas las realizaciones básicas de la Iglesia-" (20).

Lo anterior es extremadamente importante ya que muestra que la Iglesia es mucho más que la comunidad de los creyentes. Nace de la fuerza del Espíritu que hace nacer de nuevo a todos y los injerta en Cristo muerto y resucitado. A través del Espíritu de Cristo, la sociedad de los creyentes llega a ser Iglesia de Dios. Es la misma idea que aparece en 1 Pe 2, 4ss en donde se habla de ser ofrendas espirituales en la casa espiritual: se refiere a que somos templo del Espíritu que se construye por el poder del Espíritu. Todo se hace en el Espíritu Santo.

En síntesis, la Iglesia de Jesucristo es comprensible solo como el resultado de la acción salvífica de Cristo a través de su muerte y resurrección y como continuación de su actividad en el Espíritu Santo. La Iglesia tuvo su "origen del Espíritu" en la muerte y resurrección de Cristo. Allí Jesús “entregó su Espíritu” (Jn 19, 30). Pero esa relación con Cristo de parte de la Iglesia, su dependencia de él, la vida derivada de él, no puede ser comprendida en su totalidad: es el profundo misterio de la Iglesia.

Pero esta Iglesia-misterio, que es espacio posibilitador de la fe y la salvación, encuentra sus raíces más profundas en el misterio trinitario de Dios. Allí el Espíritu Santo es ese "espacio" de amor común entre el Padre y el Hijo, ese suelo nutricio, posibilitador de la entrega mutua entre el Padre y el Hijo y en donde ella misma ocurre (21). Pero a la vez, el Espíritu Santo procede de esa misma entrega mutua

(20) M. KeHL, La Iglesia..., 61.

(21) Cf. Y. CongAR, El Espíritu Santo (Barcelona 1983). 
como su resultado. En el Espíritu Santo la entrega del Padre y del Hijo adquiere un carácter personal, como un "nosotros", que a pesar de la dependencia del Padre y del Hijo, es relativamente autónomo, en cuanto persona divina y "unidad resultante de su entrega recíproca" (22). Por eso la realidad más profunda del Espíritu es ser el "Don" que posibilita la revelación. Porque en sí es amor de Dios y don de Dios es que puede revelarnos a Dios tal como es, es decir, como amor y entrega gratuita. Es el don de Dios, pero también el donante de este don que realiza de un modo personal lo que Dios es en su esencia (23). "En sentido esencial, el amor es la esencia de Dios y es propio de todas las personas divinas; en sentido personal, el amor compete al Espíritu Santo de modo especial. Él es en persona el amor recíproco del Padre y del Hijo" (24). Procede del Padre quodammodo datus, y refleja así que desde toda eternidad Dios es "donable", de modo que la condición de don y amor no solo se realiza al hacerse don en la historia, sino que es realidad ya desde toda eternidad, cuya manifestación histórica es solo fruto y reflejo de la realidad divina eterna.

Es por eso que toda revelación es fruto del Espíritu Santo, porque es fruto del amor de Dios. Pero además, por eso el Espíritu refiere siempre al Hijo y por él al Padre, porque es el fruto de la entrega mutua de ellos. El Espíritu Santo es "Dios como efusión de amor y gracia" (25). De modo que la Iglesia como templo del Espíritu es también, de un modo sacramental y derivado, ese espacio de amor común del Padre y del Hijo, que posibilita nuestra inserción en ese misterio de amor trinitario. La Iglesia es el pueblo unido "por la unidad del Padre, del Hijo y del Espíritu Santo" (LG 4). Con todo, la Iglesia, si bien puede confiar en la perpetua e infalible presencia del Espíritu Santo en su seno, no puede considerar esa presencia como una posesión automática y no sometida a la propia fidelidad. Por eso, ella no cesa de implorar su venida, lo recibe cada vez como un don gratuito, sabe que lo posee en prenda $(2$ Cor 1,22$)$ y espera su plenitud escatológica.

\section{UN ESPACIO SAGRADO QUE ES "PUEBLO"}

Este Cuerpo de Cristo y Templo del Espíritu Santo es en realidad también Pueblo. La Constitución Dogmática sobre la Iglesia, luego de haber desarrollado el origen trinitario de la Iglesia (LG 1-8), desarrolla su carácter histórico al definirla como Pueblo de Dios (LG 9-17). En efecto, esta categoría indica con fuerza el carácter peregrinante e histórico de la Iglesia (26). El designio salvífico realizado en Cristo y actualizado permanentemente por acción del Espíritu Santo, se hace presente en una comunidad de personas concretas que camina por la historia "en medio de las persecuciones del mundo y de los consuelos de Dios" (San Agustín, LG 8), hasta que llegue a la luz sin ocaso (LG 9). El misterio de Dios tiene entonces su concreción en la historia. Esto quiere decir que este Cuerpo de Cristo, espacio posibilitador de la fe por la acción del Espíritu, toma una condición concreta, de acuerdo a la

(22) M. KEHL, La Iglesia..., 63.

(23) Cf. W. KASPER, El Dios de Jesucristo (Salamanca 1985), 259s.

(24) W. KASPER, El Dios de Jesucristo..., 260.

(25) W. KASPER, El Dios de Jesucristo..., 260.

(26) R. BlazQueZ, La Iglesia del Concilio Vaticano II (Salamanca 1988), 42-44. 
situación del hombre que es "corporalidad histórica y comunitaria". Además, Pueblo de Dios es una magnitud abierta y dinámica que permite un más y un menos en la pertenencia a ese pueblo y así al misterio de Cristo y del Espíritu. Es un pueblo prefigurado en el origen del mundo, al ser creado el hombre como familia humana, preparado en la antigua alianza, constituido en Cristo, manifestado por la efusión del Espíritu Santo y que llegará gloriosamente a su plenitud al final de los siglos, cuando todos los justos, desde Adán hasta el último elegido, se reunirán con el Padre en la Iglesia universal (LG 2).

Pueblo de Dios destaca igualmente el carácter comunitario de la salvación ya que Dios "quiso santificar y salvar a los hombres no individualmente y aislados, sin conexión entre sí, sino hacer de ellos un Pueblo para que lo conociera de verdad y le sirviera con una vida santa" (LG 9). Esto muestra el carácter comunitario de la creación y de la salvación, en otras palabras, del reino que con razón es figurado como un banquete de bodas (cf. Mt 22, 1-14). Toda salvación y toda gracia son comunitarias. De allí que, como comunión, como pueblo de hermanos, como reino de Dios en germen, la Iglesia es participación en Cristo y el Espíritu (cf. 1 Jn 1, 1-3). Sin embargo, este pueblo es además sacramento de comunión, es decir, "signo e instrumento de la unión íntima con Dios y de la unidad de todo el género humano" (LG 1). Es prenda de la comunión definitiva, es realización germinal de la comunión escatológica, es adelanto de la situación final, con todas las limitaciones de su condición todavía histórica, pero con todas las gracias de su condición escatológica (LG 48). Entonces como sacramento, en su realización histórica, es realidad de comunión y además instrumento de comunión, a la par que signo. Es decir, es "espacio de salvación" en su situación concreta de ser lugar de encuentro, de ser signo visible, de poseer la condición de instrumento de la gracia, y todo esto en su condición de pueblo compuesto por hombres y mujeres de toda raza y condición.

De lo anterior podemos decir que la Iglesia, en su condición de sacramento de salvación, precisamente por ser verdaderamente pueblo es que restituye el valor salvífico a todas sus formas estructurales de existir. Si la Iglesia, como Cuerpo de Cristo y templo del Espíritu Santo, en su realidad teándrica se constituye en sacramento; pero este sacramento se despliega de manera histórica en un pueblo; entonces ese mismo pueblo, en su situación concreta de realidad formada por personas unidas socialmente por medio de formas y actividades institucionales, es el que es signo e instrumento de comunión. Pero esas estructuras institucionales no son una deformación de su realidad divina, sino un vehículo -sometido siempre a discernimiento, pero indispensable- de la acción del Espíritu (27). Esta forma institucional (Predicación o enseñanza, liturgia, ordenamiento jerárquico, servicio a los pobres, ordenamiento comunitario) es la que identifica el mensaje originario con el actual, la que integra en la unidad tanto diacrónica como sincrónica las diferentes iglesias a lo largo de la historia, y la que mantiene la identidad de la Iglesia como verdadero acontecimiento de salvación en Cristo y el Espíritu. De modo que es la realidad sacramental del Pueblo de Dios, que a su vez nace de la corporalidad asumida por el Verbo en su encarnación, la que ha renovado el valor a los distintos "espacios sagrados" de la cristiandad. 
Es cierto que Jesús "desacralizó" e incluso abolió muchos "espacios sagrados" del judaísmo: el templo, el sábado, algunos elementos de la ley (Mt 5, 33-37; 12, 1 8) (28). Efectivamente, su vida fue interpretada como decisiva, de tal manera que caducó todo sacrificio y el sacerdocio levítico (29). Cristo es ahora el único sacerdote y la única ofrenda válida que ha sido ofrecida de una vez para siempre y con valor permanente, porque permanece en su sacerdocio a la derecha del Padre, intercediendo por nosotros (Heb 7-9). En otras palabras, el cristiano no conoce otro sacerdote y otro sacrificio que no sea el de Cristo. Entonces conoce un sacerdocio y conoce un sacrificio, pero uno único y definitivo con carácter existencial y escatológico. De allí la reticencia de la Iglesia primitiva a llamar sacerdotes a sus ministros y la inexistencia de "templos" propiamente tales. La novedad de Jesús es tal que las instituciones antiguas no sirven ya más. Sin embargo, muy pronto volvieron las "formas" antiguas, que por lo demás son sumamente universales en cuanto realidades antropológicas. Es que Jesús no vino a abolir sino a cumplir (Mt 5, 17). Además, él mismo es verdadero sacerdote y sacrificio. Pero el punto es que todas esas formas recuperan su consistencia y renacen como "sagradas" solo en cuanto se vinculan con Cristo y son expresión de la sacramentalidad de la Iglesia. En cuanto son signos e instrumentos de comunión con Cristo y los hermanos.

Porque Cristo es el único templo del Espíritu es que la Iglesia es templo y es posible recurrir a los templos como signos de la realidad íntima de la Iglesia y de Cristo. En efecto, el verdadero templo es la comunidad formada por piedras vivas cuya piedra angular es el mismo Cristo (2 Pe 2, 4-10). Porque Cristo es el único sacerdote es que el pueblo de Dios es un pueblo sacerdotal, en donde todos los cristianos injertados en Cristo son también sacerdotes. Y dentro de ellos un grupo puede desempeñar de una manera representativa y vinculante, este único sacerdocio de Cristo para servicio del sacerdocio de todo el pueblo. Porque Cristo es el único sacrificio es que la Iglesia puede ofrecerlo constantemente en cuanto posee su propia presencia en la eucaristía y en los demás sacramentos que "sacralizan" los espacios de la vida al vincularlos a la pascua de Cristo. Porque Cristo es la Palabra del Padre es que su palabra y obras grabadas en la Sagrada Escritura "en cuanto escrita por inspiración del Espíritu Santo" (DV 9), son Palabra de Dios que permite el encuentro con el Hijo, son espacio de encuentro. Porque Cristo a través del Espíritu está presente en la comunidad reunida en su nombre (Mt 18,20) es que ella es espacio de encuentro con el mismo Señor resucitado. Y porque Cristo se identifica con el más pequeño de los hombres, particularmente con el pobre y sufriente, es que cada hombre es también "sacramento de Dios" y espacio de encuentro con Dios. En pocas palabras, es la realidad cristológica de la creación, y particularmente de la Iglesia, que se constituye en cuanto tal por acción del Espíritu, la que hace del mundo y de la Iglesia un espacio sagrado de encuentro por ser concreción del acontecimiento pascual.

(28) P. Tinon, Pour un chrétien, qu'est-ce qui est sacré?: Lumen vitae 54 (1999) 365-376.

(29) Cf. R. BÉRAUDY, La métamorphose du sacré religieux dans le christianisme: Lumen vitae 54 (1999) 392-403. 
En todo lugar y ocasión en que algo sea "eclesial", es por eso mismo Cuerpo de Cristo, templo del Espíritu y acontecimiento escatológico, y por eso mismo, lugar de encuentro, espacio sagrado y acontecimiento fundante.

\section{ESPACIO ESCATOLÓGICO}

Si hemos dicho que la Iglesia es espacio sagrado de encuentro, lo es de una manera especialmente honda por su índole escatológica. Efectivamente, "la restauración prometida que esperamos ya comenzó en Cristo, progresa con el envío del Espíritu Santo y por él continúa en la Iglesia... El final de la historia ha llegado ya a nosotros (cf. 1 Cor 10,11) y la renovación del mundo está ya decidida de manera irrevocable e incluso de alguna manera real ya por anticipado en este mundo. La Iglesia, en efecto, ya en la tierra, se caracteriza por una verdadera santidad, aunque todavía imperfecta. Mientras no haya nuevos cielos y nueva tierra en los que habite la justicia (cf. 2 Pe 3, 13), la Iglesia peregrina lleva en sus sacramentos e instituciones, que pertenecen a este tiempo, la imagen de este mundo que pasa. Ella misma vive entre las criaturas que gimen en dolores de parto hasta ahora y que esperan la manifestación de los hijos de Dios (cf. Rom 8, 19-22)" (LG 48).

El reino anunciado por Jesús, como irrupción de Dios en la historia, ha acontecido de una manera definitiva en la resurrección de Cristo y en la donación escatológica del Espíritu Santo a todos los creyentes en Pentecostés (Hech 2; JL 3, 1-5) (30). Y la comunidad que ha acogido este don es la ekklesía de Dios y de Cristo (1 Tes 2, 14; Hech 20, 28; 1 Cor 1, 2; 10, 32; Gál 1, 22), comunidad en posesión de los bienes escatológicos -el Espíritu Santo y la inserción en Cristo-, a cuyos miembros se les denomina por eso "los santos" (Rom 15, 25) y "los llamados" (1 Cor 1, 2). Es la comunidad del tiempo final, depositaria de las promesas del reino, ya que ha recibido el Espíritu del Resucitado que dona la vida escatológica a quien lo recibe (Hech 2, 32s). Por este Espíritu la Iglesia transmite infaliblemente los bienes del reino, a través de la Palabra y los signos sacramentales, ya que a través de ellos se hace presente el mismo Cristo resucitado con su fuerza transformante y escatológica.

Ahora bien, entre las presencias de Cristo, destaca con mucho su presencia eucarística ya que es la realización germinal de la comunión escatológica definitiva (Mc 14, 25) y es el llamado a abrir esa comunión transformadora a toda la humanidad (cf. Ef 4, 12-18). La eucaristía es esencialmente escatológica ya que anticipa el banquete eterno (Mc 14, 25), es además el ámbito donde fluye la esperanza (1 Cor 11, 26), ya que al comer un solo pan, "aun siendo muchos, un solo cuerpo somos, pues todos participamos del mismo pan" (1 Cor 10, 17), el cuerpo de Cristo resucitado. E igualmente anticipa el futuro con la transformación del presente: "Todos nosotros, que con el rostro descubierto reflejamos como en un espejo la gloria del Señor, nos vamos transformando en esa misma imagen cada vez más gloriosos: así es como actúa el Señor que es Espíritu" (2 Cor 3, 18; cf. 1 Cor 15, 51s) (31). Y

(30) M. KeHL, Escatología (Salamanca 1992), 219-230.

(31) Cf. M. GeSTEIRA, La eucaristía misterio de comunión (Salamanca ${ }^{2} 1992$ ), 589-605. 
nuevamente es el Espíritu el que realiza esta presencia eucarística de Cristo. Efectivamente, en el misterio de la salvación el Espíritu es el que realiza "la universalización de la obra de Cristo, su actualización y su personalización o interiorización" (32). La ascensión no nos separa de Cristo, sino que precisamente por ella nos adviene una cercanía y una presencia, por obra del Espíritu Santo, todavía más fuerte que antes, ya que se transforma en un encuentro personal por la interiorización de esa presencia. Es "una presencia esencialmente comunicativa, de intercomunicación vital, por la que él nos asume incorporándonos a su propia vida y nosotros vivimos por él y en él" (33). Es una presencia de comunión vital y no simplemente externa. De ahí que se pueda afirmar que el Espíritu es el que hace de la Iglesia, a través de la eucaristía, "una mística persona" (H. Mühlen) (34) en donde se da la presencia del Señor a su Iglesia, pero también de esta a aquel. El Espíritu es el vínculo de amor englobante que permite la comunión de los hombres en Cristo resucitado ( 2 Cor 13, 13; Flp 2, 1). Por eso el objetivo final de la eucaristía es la Iglesia en cuanto recepción del don de Cristo y la donación de la Iglesia a Cristo en el Espíritu Santo. Y eso es anticipo del futuro, es “espacio” escatológico, es decir, espacio de encuentro definitivo y universal, porque -al decir del mundo oriental- la Iglesia es una réplica terrena de la Iglesia celestial y la liturgia una especie de reflejo místico de la liturgia de los ángeles (35).

Esta Iglesia muestra también su ser espacio escatológico en su orientación a la transformación final (36). Esta orientación se ve, por una parte, en el ámbito antropológico: Todo bautizado participa en la vida de Cristo resucitado, lo cual es una participación en la misma vida de Dios, en la vida gloriosa del Resucitado (Rom 6, 3-11). Esto hace al bautizado estar en constante tensión hacia la plenitud de esa vida. Podemos decir que todos llevamos un tesoro en vasos de barro (2 Cor 4, 7). Y también se ve en el ámbito eclesiológico: Al incorporarnos a la Iglesia, Cuerpo de Cristo y templo del Espíritu, participamos de la vida divina, es decir, de la vida "común" de todo el Cuerpo de Cristo, y así de su plenitud escatológica que ya se cumple en los santos. Entramos en el espacio escatológico y compartimos ese lugar de encuentro. Además nos transformamos en "sacramento" del cumplimiento de esa aspiración de toda la humanidad. Cada hombre y toda la Iglesia están en el "espacio" del Resucitado, es decir, Dios les ha salido al encuentro en Cristo y se les ha donado, ha entrado en relación definitiva y salvífica con la humanidad.

(32) M. GESTEIRA, La eucaristía ..., 618

(33) M. GeSTEIRA, La eucaristía..., 618

(34) Cf. H. MüHLEn, El Espíritu Santo en la Iglesia. La Iglesia como el misterio del Espíritu Santo en Cristo y en los cristianos: "una persona en muchas personas" (Salamanca 1998).

(35) P. Tihon, La Iglesia, en H. Bourgeois - B. SEsboüÉ - P. TiHon, Los signos de la Salvación (Historia de los dogmas III) (Salamanca 1996), 322.

(36) P. MOLINARI, Índole escatológica de la Iglesia peregrinante y sus relaciones con la Iglesia del cielo, en G. BARAúnA (ED.), La Iglesia del Vaticano II. Estudios en torno a la Constitución conciliar sobre la Iglesia, II (Barcelona $\left.{ }^{3} 1968\right)$, 1143-1162. 


\section{CONCLUSIÓN}

Al concluir este recorrido podemos afirmar que si entendemos por espacio no lo que nos separa, sino precisamente lo que permite la vinculación, la relación interpersonal, entonces la Iglesia es ciertamente "espacio sagrado", en cuanto nos permite la vinculación con Dios y nos religa con el Fundamento. Sin embargo, la Iglesia, en cuanto finita y débil, en su mismo ser vinculante manifiesta que Dios está siempre más allá de ella: Dios es Dios y no es mundo. En cierto sentido Dios está presente también "por ausencia".

Por otra parte, si el espacio es lo que permite la gratuidad del don, ya que está dado y permite la relación, entonces la Iglesia, por la acción del Espíritu devenida presencia de Cristo, gracia de Dios, es espacio de encuentro de Dios con los hombres, a la manera humana, sacramental. La Iglesia, en cuanto no es una simple "cosa" en torno a mí, sino una "persona de personas" que me es dada y que es más que cada una de ellas y que yo mismo, es entonces un don gratuito, una presencia del Dios trascendente a través de coordenadas sacramentales. Y es aquí en donde entran todos los elementos antropológicos necesarios: el templo, signo visible de la comunidad, las acciones sagradas representativas del Mediador y la Palabra interpeladora expresada mediante palabra humana.

De este modo, la Iglesia es espacio sagrado en cuanto encuentro con el Fundamento de la propia existencia, pero en donde lo importante no es el "espacio" mismo, sino el Don allí recibido: Cristo. La Iglesia importa en cuanto medio que permite la donación de Dios y la fe obediente del hombre. Así la Iglesia no es fin. El único fin es Cristo y su reino. Pero el espacio de encuentro se hace necesario e indispensable (LG 14). En efecto, si fuera de la Iglesia no hay salvación es porque en realidad fuera de Cristo no hay salvación: "Porque hay un solo mediador entre Dios y los hombres, Cristo Jesús, hombre también, que se entregó a sí mismo como rescate por todos" (1 Tim 2, 5-6). El tema del espacio en el fondo es cristológico y pneumatológico.

\section{RESUMEN}

Este artículo, a la luz de LG 1, reflexiona sobre la Iglesia como espacio sagrado, es decir, como "lugar de encuentro" de los hombres con Dios y de los hombres entre sí. Espacio es precisamente lo que nos permite el encuentro, y la encarnación del Verbo es la entrada de Dios de manera definitiva y absoluta en el espacio humano. La Iglesia, como Cuerpo de Cristo y Templo del Espíritu es la presencia sacramental del Verbo en medio de la humanidad, y como tal, es lugar de encuentro con el mismo Verbo. Pero además, la Iglesia es Pueblo, es decir, esa presencia sacramental se realiza en personas y en una institucionalidad bien concreta que se transforma en instrumento de la gracia. De allí entonces que a partir de la resurrección de Cristo y de Pentecostés, el mismo Resucitado ha validado las formas institucionales concretas al hacerlas presencia y acciones de sí mismo y como tal, espacio de encuentro consigo mismo, de tal manera que la institucionalidad remita siempre más allá de sí misma, al Dios Trino. 


\begin{abstract}
This article, in the light of the LG1, reflects on the church as sacred space, that is a 'meeting place' between God and men, and of men with each other. The space is precisely what allows us to meet, and the Incarnation of the Verb is the definite and absolute coming of God into the human space. The Church, as the Body of Christ and Temple of the Holy Spirit, is the sacramental presence of the Verb amid humanity, and as such, the meeting place with Verb Himself. But the Church is also a people, so this sacramental presence is carried out by persons and in a concrete institutionality, which turns into an instrument of grace. Hence as from the Resurrection of Christ and Pentecost, the same Christ has validated the concrete institutional forms, making them presence and action of Himself, and as such, as space to meet Him, in such a way, that the institutionality always leads beyond Himself, i.e. the Trinity.
\end{abstract}

